\title{
Dry deposition fluxes and deposition velocities of seven trace metal species at five sites in central Taiwan - a summary of surrogate surface measurements and a comparison with model estimations
}

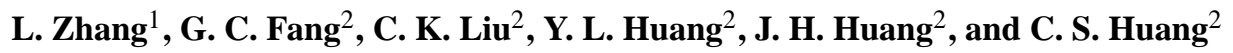 \\ ${ }^{1}$ Air Quality Research Division, Science and Technology Branch, Environment Canada, 4905 Dufferin St., Toronto, Ontario, \\ M3H5T4, Canada \\ ${ }^{2}$ Department of Safety, Health and Environmental Engineering, HungKuang University, Sha-Lu, Taichung 433, Taiwan
}

Correspondence to: G. C. Fang (gcfang@sunrise.hk.edu.tw)

Received: 31 October 2011 - Published in Atmos. Chem. Phys. Discuss.: 13 December 2011

Revised: 8 March 2012 - Accepted: 27 March 2012 - Published: 11 April 2012

\begin{abstract}
Daily air concentrations and dry deposition fluxes of seven metal species were monitored at five sites in central Taiwan for five or six days every month from September 2009 to August 2010. Annual average concentrations at the five sites were in the range of 2.8 to $3.6 \mathrm{ng} \mathrm{m}^{-3}$ for As, 25 to $82 \mathrm{ng} \mathrm{m}^{-3}$ for $\mathrm{Mn}, 1900$ to $2800 \mathrm{ng} \mathrm{m}^{-3}$ for $\mathrm{Fe}, 69$ to $109 \mathrm{ng} \mathrm{m}^{-3}$ for $\mathrm{Zn}, 18$ to $33 \mathrm{ng} \mathrm{m}^{-3}$ for $\mathrm{Cr}, 60$ to $110 \mathrm{ng} \mathrm{m}^{-3}$ for $\mathrm{Cu}$, and 25 to $40 \mathrm{ng} \mathrm{m}^{-3}$ for $\mathrm{Pb}$. Annual average dry deposition fluxes were on the order of 3, 20, 400, 50, 25, 50, and $50 \mu \mathrm{g} \mathrm{m}^{-2} \mathrm{day}^{-1}$ for $\mathrm{As}, \mathrm{Mn}, \mathrm{Fe}, \mathrm{Zn}, \mathrm{Cr}, \mathrm{Cu}$, and $\mathrm{Pb}$, respectively. Annual average dry deposition velocities $\left(V_{\mathrm{d}}\right)$ for the seven metal species ranged from 0.18 to $2.22 \mathrm{~cm} \mathrm{~s}^{-1}$ at these locations. Small seasonal and geographical variations, e.g. from a few percent to a factor of 2 for different species and/or at different locations, were found in the measured concentrations, fluxes, and $V_{\mathrm{d}} \mathrm{s}$. The measured fluxes and air concentrations had moderate to good correlations for several of the species at several of the sites (e.g. Fe, $\mathrm{Zn}$, and Mn at most of the sites), but had either weak or no correlations for the other species or at the other sites (e.g. As at Sites I and III, $\mathrm{Zn}$ and $\mathrm{Cr}$ at Site IV, and $\mathrm{Cu}$ at most of the sites). The latter cases were believed to have large uncertainties in the flux measurements using surrogate surfaces. Sensitivity tests were conducted for particle $V_{\mathrm{d}} \mathrm{s}$ using a size-segregated particle dry deposition model, assuming various combinations of three lognormal size distributions representing fine particles $\left(\mathrm{PM}_{2.5}\right)$, coarse particles $\left(\mathrm{PM}_{2.5-10}\right)$, and super-sized particles $\left(\mathrm{PM}_{10+}\right)$, respectively. It was found that the measured dry deposition fluxes can be reproduced reasonably well us-
\end{abstract}

ing the size-segregated particle dry deposition model if the mass fractions of the metal species in $\mathrm{PM}_{2.5}, \mathrm{PM}_{2.5-10}$ and $\mathrm{PM}_{10+}$ were known. Significant correlations between the modeled and the measured daily fluxes were found for those cases that were believed to have small uncertainties in the flux measurements.

\section{Introduction}

Air pollutants can be harmful to human health by the following pathways: (1) they can be absorbed into human lung tissues during breathing, and (2) they can be transported into various terrestrial and aquatic ecosystems through dry and wet deposition processes, and cause subsequent health effects when the products from these ecosystems are consumed by humans. Quantifying the amount of dry and wet deposition is critical since these deposition processes determine the pollutant species' lifetimes in air and their input to various ecosystems. Due to the expensive costs and technical difficulties associated with conducting direct measurements of dry deposition, the inferential method has been commonly used to estimate dry deposition, especially at multiple locations or at regional to global scales. Several recent studies suggested that uncertainties in dry deposition estimates are on the order of a factor of 2 , on an annual basis, for several commonly studied sulfur and nitrogen species and ozone (Flechard et al., 2011; Schwede et al., 2011). The uncertainties could be larger for particle species than for gaseous 


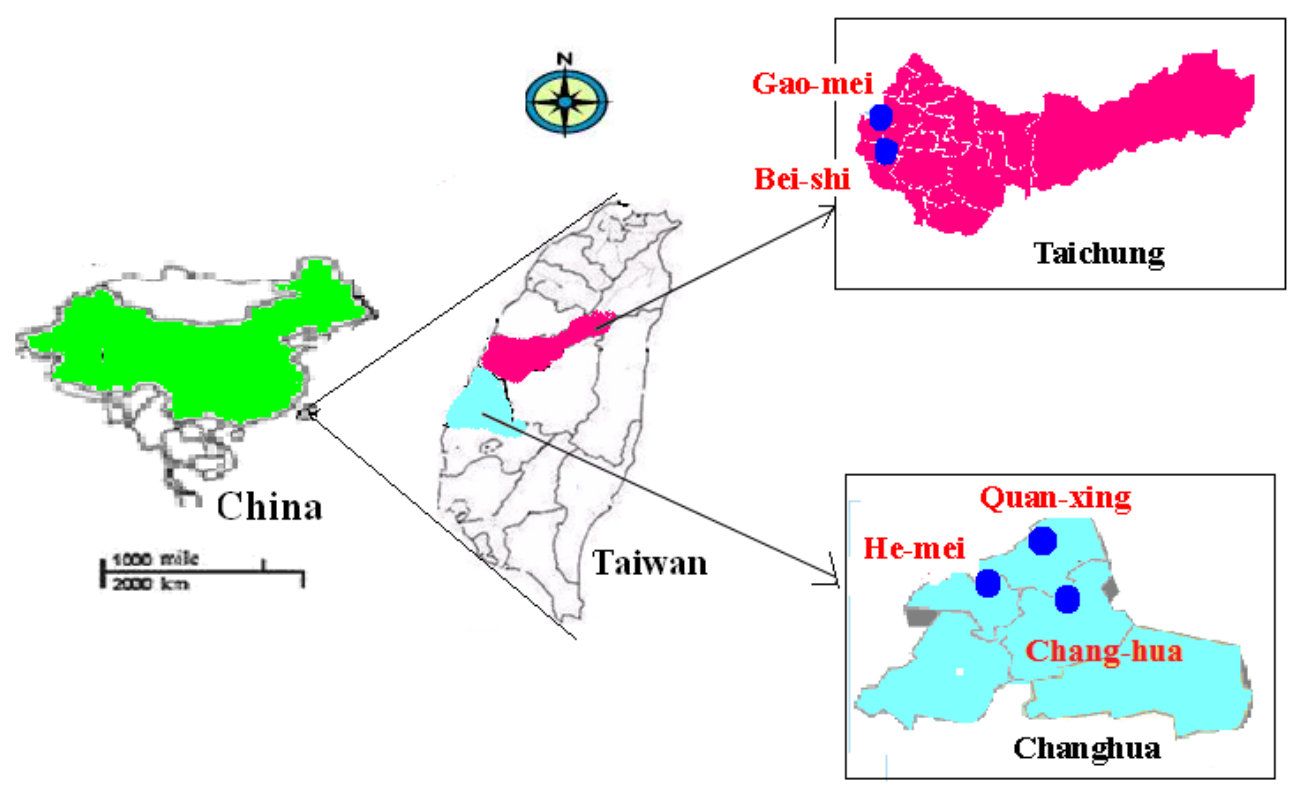

Fig. 1. Geographical location of the five sampling sites in central Taiwan.

species due to the strong dependence of the particle dry deposition velocity $\left(V_{\mathrm{d}}\right)$ on the particle size (Petroff and Zhang, 2010).

Many trace metals are toxic to humans and ecosystems and their input to surface waters and terrestrial environments need to be quantified (Rojas et al., 1993; Pirrone et al., 1995; Odabasi et al., 2002; Lu et al., 2003; Koçak et al., 2005; Sabin et al., 2006; Tasdemir et al., 2006; de P. Pereira et al., 2007; Sakata et al., 2006, 2008; Al-Momani et al., 2008). Field studies measuring metal dry deposition are limited and the $V_{\mathrm{d}} \mathrm{s}$ generated from these studies differ from each other significantly (Migon et al., 1997; Sakata and Marumoto, 2004; Tasdemir and Kural, 2005; Wu et al., 2006; Yi et al., 2001, 2006; Fang et al., 2004, 2007a, b). The differences in the measured $V_{\mathrm{d}} \mathrm{s}$ were likely caused by different meteorological conditions, different particle size distributions, and measurement uncertainties. The majority of the existing dry deposition measurements for trace metals were made using surrogate surfaces, which might not represent natural surface conditions.

The main purpose of the present study is to summarize the measured dry deposition fluxes and deposition velocities of seven metal species (As, $\mathrm{Mn}, \mathrm{Fe}, \mathrm{Zn}, \mathrm{Cr}, \mathrm{Cu}, \mathrm{Pb}$ ) collected at five sites in central Taiwan and to investigate if the measured deposition fluxes and velocities can be reproduced by a frequently-used dry deposition model of Zhang et al. (2001). It is expected that the comparison between the measurements and the model estimations can shed some light on the possible uncertainties in both the measurements and the modeling approaches. Since the dry deposition fluxes are closely linked to the air concentrations, a brief discussion of the ge- ographical and seasonal patterns of the measured air concentrations is also presented.

\section{Measurements}

\subsection{Brief description of the field experiments}

Daily air concentrations and fluxes for seven metal species (As, $\mathrm{Mn}, \mathrm{Fe}, \mathrm{Zn}, \mathrm{Cr}, \mathrm{Cu}$, and $\mathrm{Pb}$ ) were measured at five sampling sites in central Taiwan for five or six days every month for a one year period (September 2009 to August 2010). The locations of the five sampling sites are shown in Fig. 1. Although the five sites are all located in a small region (within several hundred square kilometers of each other) in central Taiwan, each site has its own characteristics and local emission sources. Briefly, Site I (Bei-shi) is a coastal suburban site with fossil fuel combustion and transportation as its major emission sources; Site II (Chang-hua) is an urban center site with transportation, chemical plant and fossil fuel combustion as major emission sources; Site III (He-mei) is a residential site with emissions from transportation, fossil fuel combustion, heating, and waste incineration; Site IV (Quanxing) is an industrial site with emissions from the steel industry, the electronic industry, the plastic industry, the chemical industry, basic metal manufacturing, machinery manufacturing, petroleum, and coal products; and Site V (Gao-mei) is a wetland site (mostly agricultural land) with emissions from a nearby Taichung thermal power plant and from fossil fuel combustion.

Total suspended particulate matter (TSP) was collected using PS-1 instruments (GPS1 Polyurethane Foam (PUF) Sampler, General Metal Work). The maximum size of the 
Table 1. Annual average ( \pm standard deviation) of the measured concentration $\left(\mathrm{ng} \mathrm{m}^{-3}\right)$, the dry deposition $\left(\mu \mathrm{g} \mathrm{m}^{-2} \mathrm{day}^{-1}\right)$ and the dry deposition velocity $\left(\mathrm{cm} \mathrm{s}^{-1}\right)$ for seven metal species (As, $\mathrm{Mn}, \mathrm{Fe}, \mathrm{Zn}, \mathrm{Cr}, \mathrm{Cu}$ and $\mathrm{Pb}$ ) in total suspended particulates at five sites during September 2009 to August 2010.

\begin{tabular}{|c|c|c|c|c|c|c|c|c|c|c|c|c|c|c|c|}
\hline & \multicolumn{5}{|c|}{ Concentration $\left(\mathrm{ng} \mathrm{m}^{-3}\right)$} & \multicolumn{5}{|c|}{ Flux $\left(\mu \mathrm{g} \mathrm{m}^{-2}\right.$ day $\left.^{-1}\right)$} & \multicolumn{5}{|c|}{ Deposition velocity $\left(\mathrm{cm} \mathrm{s}^{-1}\right)$} \\
\hline & Site I & Site II & Site III & Site IV & Site V & Site I & Site II & Site III & Site IV & Site V & Site I & Site II & Site III & Site IV & Site V \\
\hline As & $3.2 \pm 0.74$ & $3.2 \pm 0.62$ & $2.8 \pm 0.43$ & $3.6 \pm 0.52$ & $2.8 \pm 0.34$ & $2.7 \pm 0.63$ & $2.6 \pm 0.50$ & $2.9 \pm 0.48$ & $3.4 \pm 0.59$ & $2.6 \pm 0.48$ & $1.05 \pm 0.29$ & $0.97 \pm 0.20$ & $1.23 \pm 0.23$ & $1.13 \pm 0.25$ & $1.08 \pm 0.17$ \\
\hline $\mathrm{Mn}$ & $36 \pm 8.4$ & $55 \pm 13.2$ & $60 \pm 15.3$ & $82 \pm 18.4$ & $25 \pm 7.5$ & $23 \pm 4.5$ & $22 \pm 5.1$ & $20 \pm 5.8$ & $26 \pm 6.1$ & $20 \pm 6.1$ & $0.76 \pm 0.17$ & $0.46 \pm 0.08$ & $0.40 \pm 0.10$ & $0.37 \pm 0.05$ & $0.98 \pm 0.24$ \\
\hline $\mathrm{Fe}$ & $2548 \pm 960$ & $2722 \pm 669$ & $2408 \pm 657$ & $2764 \pm 648$ & $1898 \pm 571$ & $419 \pm 84$ & $420 \pm 90$ & $423 \pm 86$ & $436 \pm 109$ & $412 \pm 120$ & $0.22 \pm 0.11$ & $0.18 \pm 0.03$ & $0.22 \pm 0.08$ & $0.19 \pm 0.05$ & $0.26 \pm 0.04$ \\
\hline $\mathrm{Zn}$ & $104 \pm 31$ & $90 \pm 21$ & $94 \pm 25$ & $109 \pm 26$ & $69 \pm 20$ & $49 \pm 10$ & $50 \pm 12$ & $50 \pm 13$ & $51 \pm 16$ & $49 \pm 15$ & $0.58 \pm 0.14$ & $0.65 \pm 0.09$ & $0.63 \pm 0.12$ & $0.56 \pm 0.17$ & $0.85 \pm 0.14$ \\
\hline $\mathrm{Cr}$ & $24 \pm 6.9$ & $33 \pm 7.2$ & $24 \pm 8.2$ & $32 \pm 6.9$ & $18 \pm 5.9$ & $25 \pm 6.4$ & $25 \pm 6.4$ & $25 \pm 6.9$ & $27 \pm 6.1$ & $24 \pm 8.3$ & $1.32 \pm 0.48$ & $0.93 \pm 0.32$ & $1.35 \pm 0.59$ & $1.01 \pm 0.29$ & $1.60 \pm 0.59$ \\
\hline $\mathrm{Cu}$ & $90 \pm 27$ & $71 \pm 20$ & $79 \pm 22$ & $110 \pm 53$ & $61 \pm 17$ & $57 \pm 16$ & $47 \pm 19$ & $52 \pm 22$ & $66 \pm 18$ & $44 \pm 17$ & $0.81 \pm 0.35$ & $0.84 \pm 0.4$ & $0.82 \pm 0.36$ & $0.78 \pm 0.34$ & $0.88 \pm 0.35$ \\
\hline $\mathrm{Pb}$ & $34 \pm 13$ & $29 \pm 13$ & $32 \pm 14$ & $39 \pm 11$ & $25 \pm 11$ & $55 \pm 13$ & $45 \pm 15$ & $51 \pm 18$ & $61 \pm 17$ & $44 \pm 17$ & $2.08 \pm 0.80$ & $2.07 \pm 1.1$ & $2.07 \pm 1.10$ & $1.88 \pm 0.56$ & $2.22 \pm 1.09$ \\
\hline
\end{tabular}

collected particles was $\sim 100 \mu \mathrm{m}$. Dry deposition fluxes were collected using a surrogate surface made of polyvinyl chloride. More information on the instrument, the chemical analysis procedure and data quality control is provided in the Supplement and in Fang et al. (2007a, b).

\subsection{Air concentrations}

Annual average concentrations at the five sites were in the range of 2.8 to $3.6 \mathrm{ng} \mathrm{m}^{-3}$ for As, 25 to $82 \mathrm{ng} \mathrm{m}^{-3}$ for $\mathrm{Mn}$, 1900 to $2800 \mathrm{ng} \mathrm{m}^{-3}$ for Fe, 69 to $109 \mathrm{ng} \mathrm{m}^{-3}$ for $\mathrm{Zn}, 18$ to $33 \mathrm{ng} \mathrm{m}^{-3}$ for $\mathrm{Cr}$, 60 to $110 \mathrm{ng} \mathrm{m}^{-3}$ for $\mathrm{Cu}$, and 25 to $40 \mathrm{ng} \mathrm{m}^{-3}$ for $\mathrm{Pb}$ (Table 1). Geographical variations in the annual average concentrations were smallest for As $(<30 \%)$, in the range of $45-80 \%$ for $\mathrm{Fe}, \mathrm{Zn}, \mathrm{Cr}, \mathrm{Cu}$ and $\mathrm{Pb}$, and largest for $\mathrm{Mn}$ (a factor of 3). t-test was applied to each species to assess whether the concentrations were significantly different between sites. Significant differences between sites were found in most cases with annual means larger than $10 \%$. For example, concentrations of $\mathrm{Mn}$ had the largest geographical variations; $p$-values from t-tests were in the order of $10^{-12}$ to $10^{-29}$ between all the sites, except for the case between Sites II and III which had a p-value of 0.002 (still significantly different). For species with moderate geographical variations (e.g. $\mathrm{Zn}, \mathrm{Cr}, \mathrm{Cu}$ and $\mathrm{Pb}$ ), p-values were mainly in the order of $10^{-3}$ to $10^{-10}$; several $\mathrm{p}$-values for As were also in this range. On the other hand, $\mathrm{p}$-values in the range of $0.05-0.9$ were found in cases with small differences in annual means, e.g. between Sites I and II and between Sites III and V for As, between the first four sites for $\mathrm{Fe}$, and between Sites I and IV for $\mathrm{Zn}$ and $\mathrm{Cr}$. The standard deviation was $20-40 \%$ of the annual means for each species/site (Table 1), implying a relatively small data variability (likely due to the daily averaged data). For example, assuming an average standard deviation of $30 \%$ of its respective mean value, more than $68 \%( \pm$ one standard deviation) of the data would be in a range of a factor of 2 .

The lowest annual concentrations for all the metal species were at Site V. This is because the site was a wetland site with the smallest number of anthropogenic sources and crustal sources among all the sites. The highest annual concentrations for most metal species (except Cr) were at Site IV due to the heavily industrialized areas. Concentrations of $\mathrm{As}, \mathrm{Fe}$,
$\mathrm{Zn}, \mathrm{Cr}$ at the urban center (Site II) were similar (within a range of $10 \%$ ) to those at the industrial center (Site IV) (still significantly different for $\mathrm{AS}$ and $\mathrm{Zn}$, but not for $\mathrm{Fe}$ and $\mathrm{Cr}$ based on p-values); however, the concentrations of the other three metals species $(\mathrm{Mn}, \mathrm{Cu}$ and $\mathrm{Pb})$ were $30 \%$ smaller at Site II than those at Site IV.

It is known that metal smelting is one of the major sources of $\mathrm{Fe}, \mathrm{Mn}$ and $\mathrm{Pb}$; coal combustion is one of the major sources of $\mathrm{Cr}$; vehicle exhaust is of the major sources of $\mathrm{Cr}$, $\mathrm{Pb}, \mathrm{Cu}, \mathrm{Zn}$ and $\mathrm{Fe}$; incineration is one of the major sources of $\mathrm{Zn}$; soils and re-suspended particles are also some of the major sources of $\mathrm{Fe}$ and $\mathrm{Mn}$ (Chao and Wong, 2002; Loska and Wiechuła, 2003; Funasaka et al., 2003; Singh et al., 2005; Akhlaghi and Kompany-Zareh, 2005; Kim et al., 2006; Napier et al., 2008; Wu et al., 2010). The statistically significant geographical differences for the metal species discussed above were certainly caused by differences in local (anthropogenic and natural) sources. For example, Mn concentrations were much higher at the industrial site than at the rest of the sites, while $\mathrm{Cr}$ concentrations at the urban center and the industrial sites were basically the same.

Seasonal variations of the averaged concentrations were generally consistent from site to site, but were different depending on the metal species (Fig. 2). At the majority of the sites, most of the metal species' concentrations were lowest in summer; the highest concentrations of $\mathrm{Mn}, \mathrm{Fe}$ and $\mathrm{Zn}$ were found in winter, the highest $\mathrm{Cr}$ concentrations were in spring; $\mathrm{Pb}$ concentrations were highest in fall. Based on the standard deviation shown in Fig. 2, seasonal differences appear to be significant between the highest and the lowest seasonal averages. To verify this, t-test was applied to the two seasons with highest and lowest means for each species/site. Among the 35 cases ( 7 species $\times 5$ sites), p-values for As, Mn, Fe, $\mathrm{Zn}$ and $\mathrm{Cr}$ were all on the order of $10^{-2}$ to $10^{-4}$, except one on the order of $10^{-5}$ ( $\mathrm{Zn}$ at Site II) and another on the order of $10^{-1}$ (Cr at Site IV); p-values for $\mathrm{Cu}$ and $\mathrm{Pb}$ were all on the order of $10^{-1}$, except two on the order of $10^{-2}(\mathrm{Cu}$ at Site II and $\mathrm{Pb}$ at Site IV). Thus, seasonal variations were most significant for $\mathrm{As}, \mathrm{Mn}, \mathrm{Fe}$ and $\mathrm{Cr}$, but not for $\mathrm{Cu}$ and $\mathrm{Pb}$.

One major reason for the insignificant seasonal variations for some of the species could be due to the small changes 

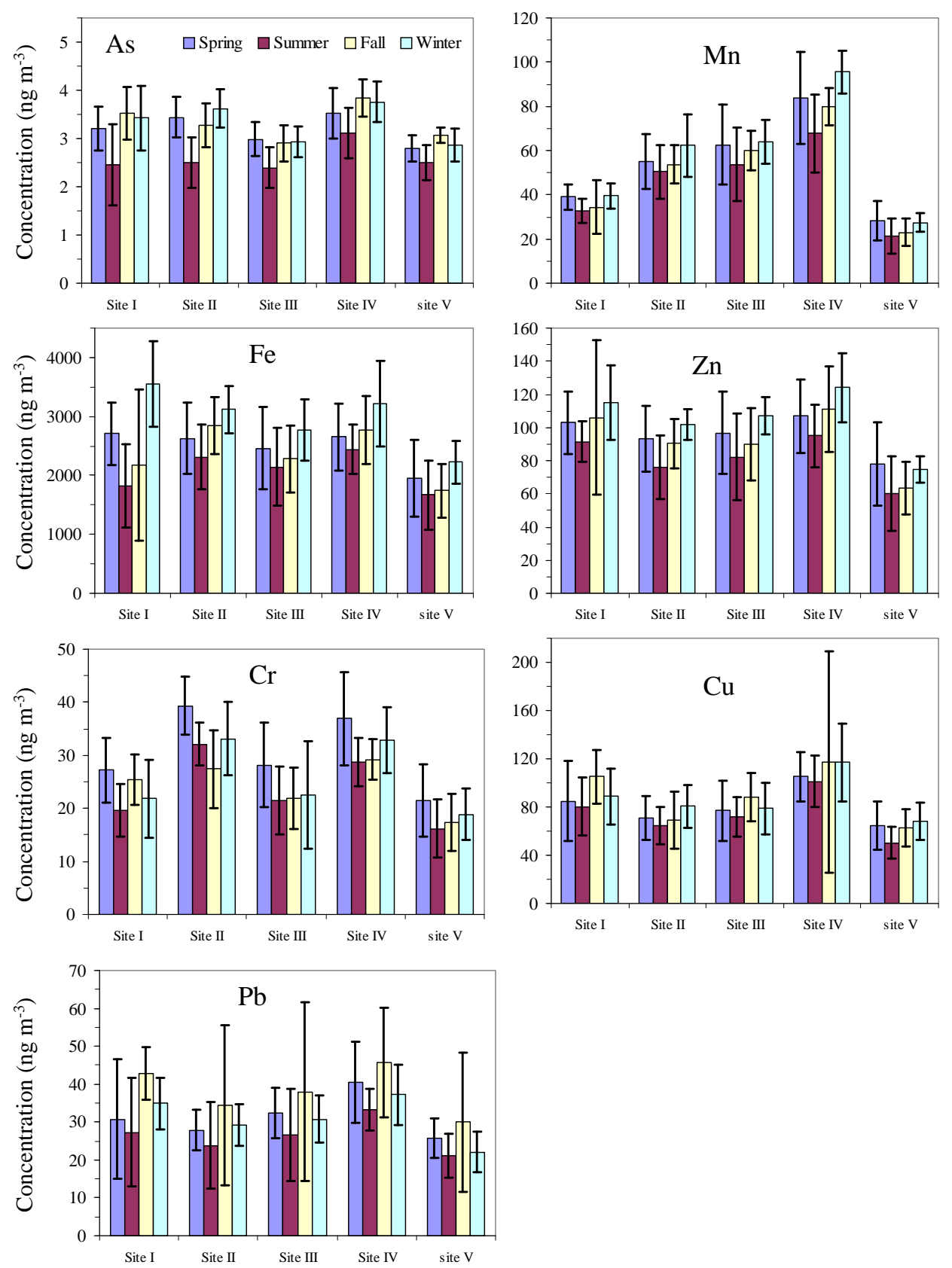

Fig. 2. Seasonal average concentrations $\left(\mathrm{ng} \mathrm{m}^{-3}\right)$ of $\mathrm{As}, \mathrm{Mn}, \mathrm{Fe}, \mathrm{Zn}, \mathrm{Cr}, \mathrm{Cu}$ and $\mathrm{Pb}$ measured at the five sites.

in meteorological conditions in this region (Table S1). Information on anthropogenic emissions inventory and sizedistribution (or fine and coarse fractions) of each metal specie are needed in order to identify the causes of the different seasonal patterns. Concentrations for the seven species obtained in the present study were similar to the order of magnitude reported from several studies conducted in other parts of the world, noting that the differences in concentrations among the existing studies could be more than one order of magnitude (Odabasi et al., 2002 and references therein).

\subsection{Dry deposition fluxes}

Average dry deposition fluxes were on the order of 3, 20, $400,50,25,50$, and $50 \mu \mathrm{g} \mathrm{m}^{-2} \mathrm{day}^{-1}$ for As, Mn, Fe, Zn, $\mathrm{Cr}, \mathrm{Cu}$, and $\mathrm{Pb}$, respectively, at the five sites. The geographical variations in the fluxes were within $30 \%$ for As, Mn, Fe, $\mathrm{Zn}$ and $\mathrm{Cr}$ but were up to $50 \%$ for $\mathrm{Cu}$ and $\mathrm{Pb}$. These flux variations were smaller than the variations in the concentrations discussed above. One of the major reasons for the reduced geographical variations in the fluxes as compared to 
the variations in the concentrations was that the largest deposition velocities were observed at Site $\mathrm{V}$, which had the lowest concentrations (more discussion about this is given below). The standard deviations shown in Table 1 (mostly $20-40 \%$ of their respective mean values) imply that the differences in the annual data between certain sites were probably statistically significant. This is confirmed by the p-values from the t-tests. For example, the p-values between Sites IV and $\mathrm{V}$ were on the order of $10^{-9}$ to $10^{-12}$ for $\mathrm{As}, \mathrm{Mn}, \mathrm{Cu}$, and $\mathrm{Pb}$ and on the order of $10^{-2}$ for $\mathrm{Fe}$ and $\mathrm{Cr}$. However, the p-values were on the order of $10^{-1}$ for the cases that had similar annual means, and therefore, the differences between these sites were insignificant (e.g. Zn between all the sites). Apparently, the flux differences between the sites were not as significant as the differences in the concentrations between the sites.

The annual fluxes obtained in the present study were well within the range of the values measured in previous studies around the world, e.g. 6 to $135 \mu \mathrm{g} \mathrm{m}^{-2}$ day $^{-1}$ for $\mathrm{Mn}, 240$ to $12090 \mu \mathrm{g} \mathrm{m}^{-2} \mathrm{day}^{-1}$ for Fe, 9 to $1910 \mu \mathrm{g} \mathrm{m}^{-2} \mathrm{day}^{-1}$ for $\mathrm{Zn}$, 1 to $53 \mu \mathrm{g} \mathrm{m}^{-2}$ day $^{-1}$ for $\mathrm{Cr}, 3$ to $190 \mu \mathrm{g} \mathrm{m}^{-2} \mathrm{day}^{-1}$ for $\mathrm{Cu}$, and 5 to $220 \mu \mathrm{g} \mathrm{m}^{-2} \mathrm{day}^{-1}$ for $\mathrm{Pb}$ (Tasdemir and Kural, 2005 and references therein).

For most of the cases, the patterns in the seasonal variations of the fluxes (Fig. S1) were similar to the patterns in the seasonal variations of the concentrations, but some differences were also found. For example, significantly higher fluxes in the fall were found for $\mathrm{Cu}$ at Sites II to V, but not in the concentrations. For most of the metal species (with the exception of $\mathrm{Cu}$ and $\mathrm{Pb}$ ), the seasonal variations of the fluxes were smaller than those of the concentrations at Sites I to IV, but the opposite was found at Site V. Again, this was caused by the much higher deposition velocities found at Site $\mathrm{V}$ compared to the other sites. The standard deviation was mostly in the range of $10-40 \%$ of its respective mean value, with a small fraction of the cases in the range of 40-80\% (e.g. $\mathrm{Cu}$ and $\mathrm{Pb}$ in the fall). The seasonal differences were statistically significant for the cases with a small standard deviation and a large difference in the seasonal means, with their p-values mostly on the order of $10^{-2}$ to $10^{-5}$. For a few of the cases, the seasonal variations were not statistically significant, with very small differences in the mean seasonal fluxes (e.g. As and Mn at Site I).

\subsection{Dry deposition velocities}

Daily dry deposition velocities $\left(V_{\mathrm{d}}\right)$ were obtained from the ratio of the measured daily fluxes and the concentrations and were then averaged into annual (Table 1) and seasonal (Fig. S2) values. Annual average $V_{\mathrm{d}} \mathrm{s}$ at the five sites ranged from 0.97 to $1.08 \mathrm{~cm} \mathrm{~s}^{-1}$ for As, 0.37 to $0.98 \mathrm{~cm} \mathrm{~s}^{-1}$ for $\mathrm{Mn}$, 0.18 to $0.26 \mathrm{~cm} \mathrm{~s}^{-1}$ for $\mathrm{Fe}, 0.56$ to $0.85 \mathrm{~cm} \mathrm{~s}^{-1}$ for $\mathrm{Zn}, 0.93$ to $1.60 \mathrm{~cm} \mathrm{~s}^{-1}$ for $\mathrm{Cr}, 0.78$ to $0.88 \mathrm{~cm} \mathrm{~s}^{-1}$ for $\mathrm{Cu}$, and 1.88 to $2.22 \mathrm{~cm} \mathrm{~s}^{-1}$ for $\mathrm{Pb}$. While $V_{\mathrm{d}} \mathrm{s}$ for a few of the metal species only changed slightly from site to site, the $V_{\mathrm{d}} \mathrm{s}$ for the other species changed significantly (e.g. by a factor of 2). Since all of the five sites were located within a few hundred square kilometres of each other, meteorological conditions differed only slightly from site to site (Table $\mathrm{S} 1$ ). This explains the small differences in the $V_{\mathrm{d}} \mathrm{s}$ from site to site for a few of the metal species (e.g. As, $\mathrm{Fe}, \mathrm{Cu}$ ). The very large difference in the $V_{\mathrm{d}} \mathrm{s}$ from site to site for a few of the species (e.g. Mn and Cr) could thus be caused by their different size distributions at the different sites, considering the strong dependence of the $V_{\mathrm{d}}$ on the particle size distribution (more discussion on this in Sect. 3). The site differences were statistically significant; p-values between the sites, with the highest and lowest mean $V_{\mathrm{d}}$ values on the order of $10^{-7}$ to $10^{-24}$ for $\mathrm{As}, \mathrm{Mn}, \mathrm{Fe}$, $\mathrm{Zn}$, and $\mathrm{Cr}$, and on the order of $10^{-2}$ for $\mathrm{Cu}$ and $\mathrm{Pb}$.

The seasonal variations in the $V_{\mathrm{d}}$ s were small (e.g. $10 \%$ or less) for many of the species and at most of the sites. Again, this can be explained by the small seasonal differences in the meteorological conditions since all of the sites were located in a tropical region. However, the seasonal variations, as large as a factor of 2, were found for $\mathrm{Cu}$ at Site II and for $\mathrm{Pb}$ at Sites II, III, and V. The size distributions of particles could be the major cause for this, as explained above. The uncertainties in the flux measurements for these two species were also suspected to be larger than for the other species, as discussed in Sect. 2.5. It was also observed that, in this study, the $V_{\mathrm{d}}$ values of $\mathrm{Fe}$ were much smaller than those of $\mathrm{Pb}$. This was consistent with one of our earlier studies (Fang et al., 2007a), but contrary to a few of our other earlier studies (Fang et al., 2004, 2007b), all of which were conducted using the same instruments but were at other locations in Taiwan. The different size distributions at the different locations (especially the mass fraction of particles larger than $10 \mu \mathrm{m}$, as discussed in Sect. 3) were suspected to be the major cause of the large differences in the $V_{\mathrm{d}} \mathrm{S}$ of Fe. Seasonal differences were statistically significant, with p-values being mostly on the order of $10^{-2}$ to $10^{-5}$; however, a few cases were found to be insignificant based on p-values on the order of $10^{-1}$ (e.g. As at Site 1 and $\mathrm{Mn}$ at all of the sites).

The annual average $V_{\mathrm{d}}$ s for the seven metal species obtained in the present study $\left(0.18\right.$ to $\left.2.22 \mathrm{~cm} \mathrm{~s}^{-1}\right)$ were within the range of previous field studies of trace metals. For example, Yi et al. (2001) obtained $V_{\mathrm{d}} \mathrm{s}$ ranging from 0.2 to $12 \mathrm{~cm} \mathrm{~s}^{-1}$ for various crustal and anthropogenic elements; Odabasi et al. (2002) obtained $V_{\mathrm{d}} \mathrm{s}$ of $1.0-6.2 \mathrm{~cm} \mathrm{~s}^{-1}$ for various metal species (including all of the species studied here except As). On the other hand, Tasdemir and Kural (2005) obtained $V_{\mathrm{d}} \mathrm{s}$ of 2.3 to $11.1 \mathrm{~cm} \mathrm{~s}^{-1}$ for 13 trace elements and their values were all higher than the values presented in this study. Apparently, large differences existed in the $V_{\mathrm{d}}$ values from the different studies and were more than likely caused by a combination of different particle size distributions, different meteorological conditions, and measurement uncertainties. It should be noted here that the $V_{\mathrm{d}} \mathrm{s}$ to the natural surface could differ significantly from those to the surrogate surfaces that were used in this study. 


\subsection{Correlation between measured fluxes and concentrations}

The dry deposition fluxes of a pollutant strongly depend on its air concentrations. Thus, theoretically, measured fluxes and concentrations should have a strong correlation (e.g. Yi et al., 2006). In theory, species with small variations in their $V_{\mathrm{d}}$ should have a better correlation between their flux and their concentration since the change in the flux is primarily due to the change in the concentration. However, two factors might decrease the correlation. The first factor is related to the measurement errors caused by the uncertainties of the instruments that are collecting the metal species and the subsequent analytical artifacts. The second factor is the validity of the assumption that a surrogate surface represents the natural surfaces in the collection of pollutant species (i.e. if the collected mass represents the real dry deposition fluxes). If the instrument-related errors are assumed to be relatively small, the second factor could be the major cause of any poor correlations between the measured concentrations and fluxes. Such an analysis could provide an assessment of the suitability of using surrogate surfaces for the dry deposition measurements.

Figure 3 shows the flux-concentration regression equations for $\mathrm{Mn}$ at the five sites as an example and Fig. S3 illustrates the same information for the other six metal species. The extremely small p-values for Mn at Sites II to V suggest that there is a significant correlation between the fluxes and the concentrations. The square of correlation coefficient $\left(R^{2}\right)$ ranged from 0.34 to 0.58 at these four sites, suggesting that $34-58 \%$ of the variations in the fluxes can be explained by the variations in the concentrations. However, the correlation between the fluxes and the concentrations for $\mathrm{Mn}$ at Site I was extremely low (small $R^{2}$ and large p-value). Looking at the other six species, moderate to good correlations (based on $R^{2} \geq 0.4$ and $p<0.1$ ) were identified for As at Site V; Fe at Sites I, II, and V; and Zn at Sites II, III, and V. No correlation (based on $R^{2}<0.1$ and $p>0.1$ ) was identified for As at Sites I and IV; Cr at Site IV; and Cu at Sites I, II, and IV. Weak correlations were identified for the rest of the cases.

Theoretically, strong correlations should exist simultaneously between the flux and the air concentration and between the flux and the $V_{\mathrm{d}}$. Under extreme conditions, the correlations can be weak. For example, if every low concentration corresponded to a large $V_{\mathrm{d}}$ (and vice versa), the flux would be close to a constant). Another example would be if the concentration (or $V_{\mathrm{d}}$ ) stayed constant and all of the variations in the fluxes were explained by variations in the $V_{\mathrm{d}}$ (or the concentration); in this situation, the flux and the concentration (or $V_{\mathrm{d}}$ ) would have no correlation but the flux and the $V_{\mathrm{d}}$ (or concentration) would have a perfect correlation. These extreme conditions are unlikely in the real world and are certainly not the case for the present data set, as can be seen by the fact that the magnitudes of the variations in the fluxes, concentrations and $V_{\mathrm{d}}$ values are all similar (compare

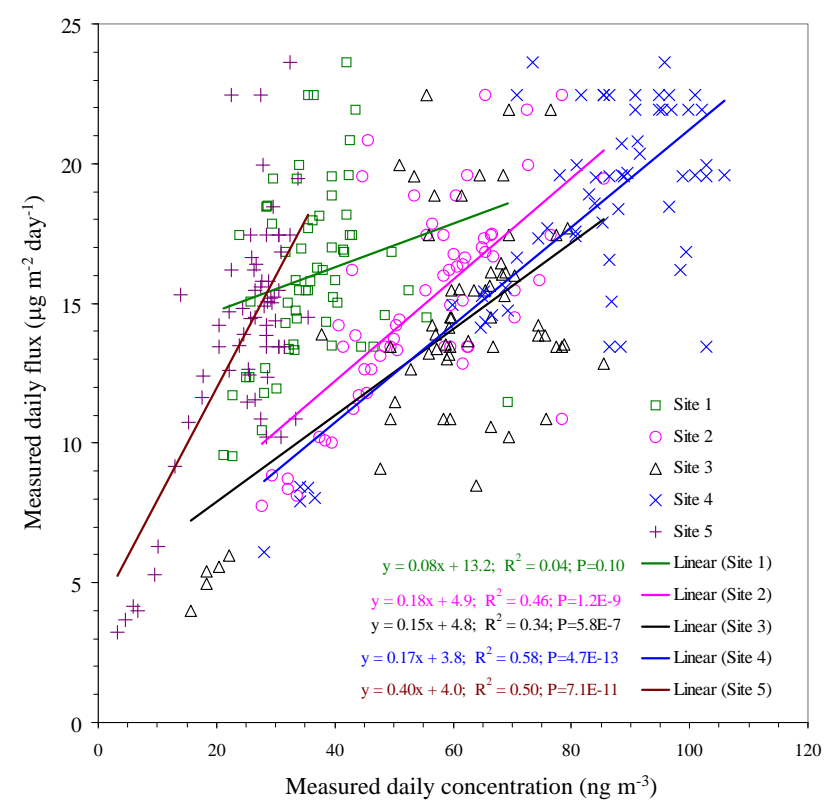

Fig. 3. Correlation between measured daily fluxes $\left(\mu \mathrm{g} \mathrm{m}^{-2}\right.$ day $\left.^{-1}\right)$ and measured daily concentrations $\left(\mathrm{ng} \mathrm{m}^{-3}\right)$ for $\mathrm{Mn}$ at the five sites.

the standard deviations with their respective mean values, as discussed in Sects. 2.2-2.4). Large variations in the particle size distributions, if they were present during the measurement periods, should have contributed to the large variations in the $V_{\mathrm{d}} \mathrm{s}$. Yet, the variation in the measured $V_{\mathrm{d}} \mathrm{s}$ was relatively small and can therefore only explain a portion of the variation in the measured fluxes. Thus, a low or zero correlation between the fluxes and the concentrations was more than likely caused by the uncertainties in the measurements. There is a high probability that the uncertainties or errors in the surrogate surface flux measurements were larger than the uncertainties from other sources. On the other hand, the cases with moderate-to-good correlations that were mentioned above have also provided a degree of confidence to the quality of the fluxes measured using surrogate surfaces.

\section{Model estimates}

\subsection{Brief review of size distributions of metal species}

Due to the strong dependence of the dry deposition velocity $\left(V_{\mathrm{d}}\right)$ on particle size, knowledge of particle size distribution (PSD) is extremely important in particle dry deposition studies. Measurements of PSD are limited for many of the metal species. A detailed review of PSD of Pb-containing atmospheric particles was recently conducted by Cho et al. (2011). The PSD of several other metals is briefly reviewed here so that the information can be used for modeling their dry deposition, as well as for other air pollution studies. 
PSD data collected at three background sites in the UK showed three types of PSD: (1) A major mode at $\sim 0.5 \mu \mathrm{m}$ and additional minor modes at 1.2 and $6.0 \mu \mathrm{m}$ or at 3.5 and $20 \mu \mathrm{m}$, depending on locations, for $\mathrm{Cd}, \mathrm{Sn}, \mathrm{Pb}$, and $\mathrm{Se}$; (2) multiple modes throughout the size range and more evenly distributed mass for $\mathrm{Ni}, \mathrm{Zn}, \mathrm{Cu}, \mathrm{Co}, \mathrm{Mn}$, and $\mathrm{Hg}$; (3) a large mode at $\sim 3-4 \mu \mathrm{m}$ for $\mathrm{Fe}, \mathrm{Sr}$, and Ba (Allen et al., 2001). The same study also showed that particles larger than $10 \mu \mathrm{m}$ could contribute $10-20 \%$ to the total mass for several of the species considered in the present study (e.g. $\mathrm{Mn}, \mathrm{Fe}, \mathrm{Zn}, \mathrm{Cu}$ ). PSD measurements in a residential area (Kyoto, Japan) showed a typical bimodal distribution with $\mathrm{S}, \mathrm{Zn}$, and $\mathrm{Pb}$ found predominantly as fine particles (peaking at $0.5-1 \mu \mathrm{m}$ ); $\mathrm{Si}$, Ca, $\mathrm{Fe}$, and $\mathrm{Ti}$ found predominantly as coarse particles (peaking at $\sim 5 \mu \mathrm{m}$ ); and $\mathrm{K}, \mathrm{V}, \mathrm{Cr}, \mathrm{Mn}, \mathrm{Ni}, \mathrm{Cu}$, and $\mathrm{Br}$ evenly distributed as both fine and coarse fractions (peaking at 0.51 and $5 \mu \mathrm{m}$ ) (Kasahara et al., 1996). Both unimodal (either as fine or coarse particles) and bimodal (one fine and one coarse) PSD have been found in an urban environment (Brüggemann et al., 2009).

Size-fractionated data were produced in several studies, although PSD profiles were not generated (e.g. Monarca et al., 1997; Singh et al., 2002; Turšič et al., 2006; Wang et al., 2006; Yi et al., 2006; Karanasiou et al., 2007). A few studies have investigated mass fractions of the commonly-defined size ranges (e.g. $\mathrm{PM}_{1.0}, \mathrm{PM}_{2.5}, \mathrm{PM}_{10}$ ) (Zota et al., 2009; Makkonen et al., 2010). These studies have suggested that fine particles dominate the total mass in some cases (species or locations) while coarse particles dominate the total mass in other cases. One study investigated the fraction of $\mathrm{PM}_{10}$ in TSP (de Pereira et al., 2007) and showed that particles larger than $10 \mu \mathrm{m}$ could contribute up to $20-30 \%$ of the TSP mass at some locations.

Mass median diameter (MMD) from the data collected at an urban site in Japan (Tokyo) were in the range of 0.92 to $1.4 \mu \mathrm{m}$ for $\mathrm{Cd}, 1.0-1.5 \mu \mathrm{m}$ for $\mathrm{Pb}, 1.2$ to $2.0 \mu \mathrm{m}$ for $\mathrm{Zn}$, 2.9 to $3.9 \mu \mathrm{m}$ for $\mathrm{Cu}$, and 2.5 to $4.1 \mu \mathrm{m}$ for Mn (Sakata and Marumoto, 2004). In another study conducted in an urban environment (at a roadside), the MMD data was in the following order: $\mathrm{Pb}(0.91)<\mathrm{Cd}(1.14)<\mathrm{V}(1.38)<\mathrm{Ni}(1.54)<\mathrm{Cu}$ (2.04) $<\operatorname{Mn}(2.61)<\operatorname{Cr}(2.91)<\mathrm{Fe}$ (3.82) (Samara and Voutsa, 2005). The knowledge discussed above relating to the size distributions was used below for estimating the $V_{\mathrm{d}}$ s for the seven metal species.

\subsection{Modeled dry deposition velocities}

The literature review presented in Sect. 3.1 suggests that most metal species have more than one mode in their size distributions. For the seven species considered in the present study, both fine and coarse particles are important to the total mass. Particles larger than $10 \mu \mathrm{m}$ could also contribute between a few percent to $20 \%$ to the total mass.

To model $V_{\mathrm{d}}$ as accurately as possible, a full size distribution was needed, as suggested in several previous studies
Table 2. Different combinations of Size 1, Size 2, and Size 3 (in percentage) for $V_{\mathrm{d}}$ sensitivity tests (Size 4 to Size 10) and for $V_{\mathrm{d}}$ and F calculations of seven metal species. Size 1, Size 2 and Size 3 are three single lognormal size distributions representing $\mathrm{PM}_{2.5}$, $\mathrm{PM}_{2.5-10}$, and $\mathrm{PM}_{10+}$, respectively, as shown in Fig. S4.

\begin{tabular}{|c|c|c|c|c|c|c|c|}
\hline \multicolumn{8}{|c|}{ For sensitivity tests } \\
\hline & Size 4 & Size 5 & Size 6 & Size 7 & Size 8 & Size 9 & Size 10 \\
\hline Size 1 & 80 & 50 & 20 & 80 & 50 & 40 & 30 \\
\hline Size 2 & 20 & 50 & 80 & 10 & 40 & 40 & 40 \\
\hline Size 3 & 0 & 0 & 0 & 10 & 10 & 20 & 30 \\
\hline \multicolumn{8}{|c|}{ For dry deposition calculation at all sites } \\
\hline & As & $\mathrm{Mn}$ & $\mathrm{Fe}$ & $\mathrm{Zn}$ & $\mathrm{Cr}$ & $\mathrm{Cu}$ & $\mathrm{Pb}$ \\
\hline Size 1 & 40 & 50 & 20 & 50 & 30 & 45 & 40 \\
\hline Size 2 & 40 & 40 & 80 & 40 & 50 & 40 & 30 \\
\hline Size 3 & 20 & 10 & 0 & 10 & 20 & 15 & 30 \\
\hline \multicolumn{8}{|c|}{ For dry deposition calculation at Site V only } \\
\hline & & $\mathrm{Mn}$ & $\mathrm{Fe}$ & $\mathrm{Zn}$ & $\mathrm{Cr}$ & & \\
\hline Size 1 & & 40 & 20 & 45 & 20 & & \\
\hline Size 2 & & 40 & 78 & 40 & 50 & & \\
\hline Size 3 & & 20 & 2 & 15 & 30 & & \\
\hline
\end{tabular}

(Holsen and Noll, 1992; Paode et al., 1998; Sofuoglu et al., 1998). In the present study, three lognormal size distributions representing the fine mode $\left(\mathrm{PM}_{2.5}\right)$ (referred to as Size 1 in Table 2), the coarse mode $\left(\mathrm{PM}_{2.5-10}\right)$ (referred to as Size 2), and the large mode $\left(\mathrm{PM}_{10+}\right)$ (referred to as Size 3 ), respectively, were first assumed. The geometric mass median diameter and geometric standard deviation were chosen as $0.45 \mu \mathrm{m}$ and 2.0, respectively, for Size 1; $4.5 \mu \mathrm{m}$ and 1.6 for Size 2; and $20 \mu \mathrm{m}$ and 1.6 for Size 3 (see their size distributions in Fig. S4). Size-segregated $V_{\mathrm{d}}$ was calculated using the model of Zhang et al. (2001) with modifications to the handling of seasonal-dependent input parameters (Zhang et al., 2003) (see SI for a brief description of the model). The size-segregated $V_{\mathrm{d}}$ was then averaged into bulk $V_{\mathrm{d}} \mathrm{s}$ based on the size distributions of the Size 1, Size 2, and Size 3. Different combinations of these three modes, which could represent the different metal species' size distributions, were then designed to see how sensitive the bulk $V_{\mathrm{d}}$ is to the size distributions (Size 4 to Size 10 listed in Table 2). Daily meteorological data (wind speed, relative humidity, and temperature) were obtained from nearby meteorological stations and were used in the $V_{\mathrm{d}}$ calculations.

Modeled annual average $V_{\mathrm{d}} \mathrm{s}$ at the five sites ranged from 0.09 to $0.19 \mathrm{~cm} \mathrm{~s}^{-1}$ for Size 1 ; from 0.20 to $0.22 \mathrm{~cm} \mathrm{~s}^{-1}$ for Size 2; and from 3.75 to $4.58 \mathrm{~cm} \mathrm{~s}^{-1}$ for Size 3. Different meteorological conditions and underlying surface types among the five sites caused a factor of 2 difference in the modeled $V_{\mathrm{d}}$ of Size 1, but only caused a small difference (e.g. $\sim 20 \%$ or less) in those of Size 3 and almost no differences in those of Size 2. While the $V_{\mathrm{d}} \mathrm{s}$ of Size 2 were slightly higher (by $10 \%$ to a factor of 2) than those of Size 1 , the $V_{\mathrm{d}} \mathrm{s}$ of Size 3 
Table 3. Modeled deposition velocities (mean and standard deviation, $\mathrm{cm} \mathrm{s}^{-1}$ ) for 10 particle size distributions listed in Table 2 at the five sites.

\begin{tabular}{llcccccccccc}
\hline & & Size 1 & Size 2 & Size 3 & Size 4 & Size 5 & Size 6 & Size 7 & Size 8 & Size 9 & Size 10 \\
\hline Site I & Mean & 0.12 & 0.20 & 3.75 & 0.14 & 0.16 & 0.18 & 0.49 & 0.51 & 0.88 & 1.24 \\
& Stdv & 0.04 & 0.01 & 0.34 & 0.04 & 0.03 & 0.02 & 0.07 & 0.06 & 0.09 & 0.12 \\
Site II & Mean & 0.14 & 0.20 & 3.96 & 0.15 & 0.17 & 0.19 & 0.53 & 0.55 & 0.93 & 1.31 \\
& Stdv & 0.05 & 0.02 & 0.56 & 0.05 & 0.04 & 0.02 & 0.10 & 0.09 & 0.14 & 0.19 \\
Site III & Mean & 0.19 & 0.22 & 4.58 & 0.20 & 0.21 & 0.22 & 0.64 & 0.64 & 1.08 & 1.52 \\
& Stdv & 0.07 & 0.03 & 0.93 & 0.06 & 0.05 & 0.04 & 0.15 & 0.14 & 0.23 & 0.31 \\
Site IV & Mean & 0.19 & 0.21 & 4.31 & 0.19 & 0.20 & 0.21 & 0.60 & 0.61 & 1.02 & 1.44 \\
& Stdv & 0.08 & 0.02 & 0.88 & 0.07 & 0.05 & 0.04 & 0.15 & 0.14 & 0.22 & 0.30 \\
Site V & Mean & 0.09 & 0.20 & 3.82 & 0.11 & 0.14 & 0.17 & 0.46 & 0.49 & 0.85 & 1.21 \\
& Stdv & 0.04 & 0.02 & 0.44 & 0.04 & 0.04 & 0.04 & 0.11 & 0.11 & 0.19 & 0.27 \\
\hline
\end{tabular}

were more than one order of magnitude higher than those of Size 1 and Size 2.

Due to the small $V_{\mathrm{d}}$ values for both Sizes 1 and 2, the $V_{\mathrm{d}} \mathrm{s}$ for the various combinations of Size 1 and Size 2 (e.g. Sizes 4, 5, and 6 in Tables 2 and 3) were all smaller than $0.22 \mathrm{~cm} \mathrm{~s}^{-1}$ at all of the sites. Assuming that $10 \%$ of the total mass was from particles larger than $10 \mu \mathrm{m}\left(\mathrm{PM}_{10+}\right)$ (e.g. Size 7 and Size 8), the bulk of the $V_{\mathrm{d}}$ S for TSP could then be increased to 0.46 to $0.64 \mathrm{~cm} \mathrm{~s}^{-1}$ at all of the sites. If the mass fraction of $\mathrm{PM}_{10+}$ is larger than $20 \%$, the bulk $V_{\mathrm{d}} \mathrm{S}$ for TSP could be higher than $1 \mathrm{~cm} \mathrm{~s}^{-1}$ (Size 9 and Size 10). Apparently, a small percentage of $\mathrm{PM}_{10+}$ mass contributed significantly to the bulk $V_{\mathrm{d}}$ for TSP. A field study measuring metal dry deposition fluxes using surrogate surfaces has also suggested the importance of the role of the contribution of large particles to the total fluxes (Zufall et al., 1998).

Since the size distributions for the metals measured in the present study were not available, some assumptions were needed in order to calculate their $V_{\mathrm{d}} \mathrm{s}$. Based on the sensitivity tests presented in Table 3 and the review of size distributions presented in Sect. 3.1, size distributions created from a combination of Size 1, Size 2, and Size 3 were proposed for several of the metal species (Table 2). It is noted that the $V_{\mathrm{d}} \mathrm{s}$ for a few of the species (Mn, Fe, Zn, and Cr) at Site V differed significantly from the the $V_{\mathrm{d}} \mathrm{s}$ at the other four sites; thus different size distributions for theses species were used for Site V (Table 2).

The modeled daily $V_{\mathrm{d}} \mathrm{s}$ did not generally have any correlations with the measured daily $V_{\mathrm{d}} \mathrm{s}$ for most of the species and at most of the sites (figure not presented). This could be due to the large uncertainties in the modeled $V_{\mathrm{d}} \mathrm{s}$ as a result of the various assumptions; the large uncertainties in the measured fluxes using surrogate surfaces; and to some extent, to the uncertainties in the measured air concentrations, where the latter two variables were used for obtaining the measured $V_{\mathrm{d}} \mathrm{s}$. However, annual average $V_{\mathrm{d}} \mathrm{s}$ for all of the species (with the exception of $\mathrm{Pb}$ ) agreed very well with the measured $V_{\mathrm{d}} \mathrm{S}$ (e.g. only $10 \%$ differences in many of the cases as shown in Fig. 4). For $\mathrm{Pb}$, the modeled $V_{\mathrm{d}} \mathrm{s}$ were $30-50 \%$ smaller than the measured values. When all the species are considered together, good correlations between modeled and measured annual $V_{\mathrm{d}}$ values were found (the last panel in Fig. 4). However, it should be pointed out that the differences between the modeled and the measured $V_{\mathrm{d}}$ values were statistically significant, with the $\mathrm{p}$-values from the $\mathrm{t}$-tests being on the order of $10^{-2}$ to $10^{-25}$.

While the assumed size distributions for most of the species can be easily justified based on previous measurements, as reviewed in Sect. 3.1, we do not have much confidence for two of the species ( $\mathrm{Fe}$ and $\mathrm{Pb}$ ). As discussed in Sect. 3.1, the geometric mass median diameter (MMD) was largest for $\mathrm{Fe}$ and smallest for $\mathrm{Pb}$; however, for the measured $V_{\mathrm{d}} \mathrm{S}$ in the present study, the smallest values were for $\mathrm{Fe}$ and the largest values were for $\mathrm{Pb}$. For $\mathrm{Fe}$, the modeled $V_{\mathrm{d}} \mathrm{s}$ can be made very close to the measured $V_{\mathrm{d}} \mathrm{s}$ (as shown in Fig. 4) if the mass fraction of $\mathrm{PM}_{10+}$ is limited to a very small percentage (e.g. $2 \%$ or less), while assuming a large fraction of $\mathrm{PM}_{2.5-10}$ (e.g. $80 \%$ in Table 2), in order to satisfy the very large measured MMD values. However, it is difficult to obtain modeled $V_{\mathrm{d}} \mathrm{s}$ as high as the measured $V_{\mathrm{d}} \mathrm{s}$ for $\mathrm{Pb}$ (as shown in Fig. 4) despite an assumption of a $30 \%$ mass fraction of $\mathrm{PM}_{10+}$.

There were several possibilities of the cause of the large differences between the modeled and measured $V_{\mathrm{d}} \mathrm{s}$ for $\mathrm{Pb}$ : (1) the measured $V_{\mathrm{d}}$ was overestimated due to the use of a surrogate surface; (2) the MMD assumed for the $\mathrm{PM}_{2.5}$ fraction for $\mathrm{Pb}$ was too large (noting that $V_{\mathrm{d}}$ increases with a decrease in particle size for very small particles); (3) the modeled $V_{\mathrm{d}}$ was underestimated using daily-averaged meteorological data (note that the daytime wind speed could be much higher than the daily-averaged wind speed and that the $V_{\mathrm{d}} \mathrm{s}$ for small particles are more sensitive to wind speed). These factors can be identified in future studies with more accurate data of the mass size fraction and meteorological variables. 

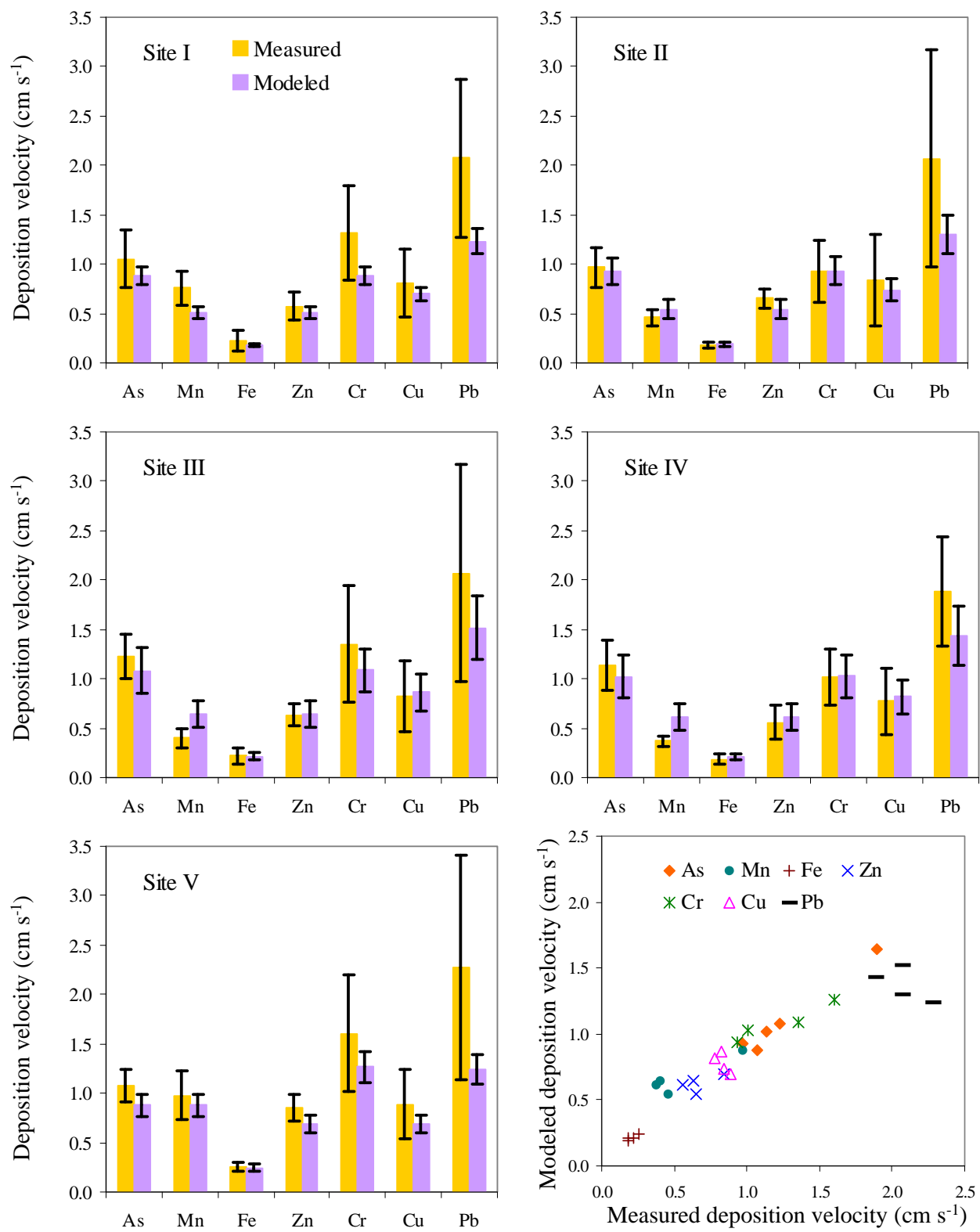

Fig. 4. Annual average of measured and modeled deposition velocities $\left(\mathrm{cm} \mathrm{s}^{-1}\right)$ of $\mathrm{As}, \mathrm{Mn}, \mathrm{Fe}, \mathrm{Zn}, \mathrm{Cr}, \mathrm{Cu}$, and $\mathrm{Pb}$ at the five sites and the scatter plot of these values.

\subsection{Modeled fluxes and comparison with measurements}

To support the discussions presented in Sect. 2.5 above, correlations between the modeled fluxes and the measured concentrations were conducted (see one example shown in Fig. 5). As expected, the modeled fluxes had good correlations with the measured fluxes at all of the sites; the square of the correlation coefficient was higher than 0.8 at two of the sites. A comparison of the values shown in Fig. 5 with those shown in Fig. 3 demonstrated that the correlations between the modeled fluxes and the measured concentrations were much better than those between the measured fluxes and the concentrations at four of the sites; the only exception is at Site IV, for which the correlation actually declined. In general, the modeled fluxes correlated reasonably well with the measured concentrations for all of the species (figure not present).

The modeled and the measured annual average fluxes and the correlations between the daily values of the modeled and the measured fluxes are presented in Table 4 . The correlation coefficient $(R)$, the F-value (a test for the statistical significance of the regression, obtained by dividing the explained variance by the unexplained variance), and the significance of the correlation $P(F)$ (the probability that the two group 
Table 4. Measured and modeled annual dry deposition fluxes $\left(\mu \mathrm{g} \mathrm{m}^{-2} \mathrm{day}^{-1}\right)$ and the regression analysis between modeled and measured values.

\begin{tabular}{|c|c|c|c|c|c|c|c|c|}
\hline & & As & $\mathrm{Mn}$ & $\mathrm{Fe}$ & $\mathrm{Zn}$ & $\mathrm{Cr}$ & $\mathrm{Cu}$ & $\mathrm{Pb}$ \\
\hline \multirow[t]{5}{*}{ Site I } & Measured & 2.7 & 23.0 & 419 & 49.4 & 25.2 & 57.0 & 54.9 \\
\hline & Modeled & 2.4 & 16.0 & 398 & 45.7 & 17.8 & 53.9 & 35.9 \\
\hline & R-correlation & 0.31 & & 0.55 & 0.35 & 0.33 & & \\
\hline & F-value & 6.4 & & 25.4 & 8.5 & 7.5 & & \\
\hline & $P(F)$ & 0.014 & & $4.6 \times 10^{-6}$ & 0.005 & 0.008 & & \\
\hline \multirow[t]{5}{*}{ Site II } & Measured & 2.6 & 21.6 & 420 & 50.4 & 25.3 & 47.2 & 45.4 \\
\hline & Modeled & 2.5 & 25.7 & 439 & 41.8 & 26.5 & 45.1 & 32.6 \\
\hline & R-correlation & & 0.46 & 0.60 & 0.55 & & & 0.47 \\
\hline & F-value & & 15.7 & 34.2 & 25.7 & & & 17.0 \\
\hline & $P(F)$ & & 0.0002 & $2.2 \times 10^{-7}$ & $4.2 \times 10^{-6}$ & & & 0.0001 \\
\hline \multirow[t]{5}{*}{ Site III } & Measured & 2.9 & 20.3 & 423 & 50.3 & 24.8 & 52.4 & 50.5 \\
\hline & Modeled & 2.6 & 32.8 & 442 & 51.5 & 21.7 & 58.1 & 41.7 \\
\hline & R-correlation & & 0.39 & 0.25 & 0.53 & 0.32 & & 0.43 \\
\hline & F-value & & 10.9 & 4.0 & 23.5 & 6.8 & & 13.3 \\
\hline & $P(F)$ & & 0.0017 & 0.05 & $9.1 \times 10^{-6}$ & 0.011 & & 0.0005 \\
\hline \multirow[t]{5}{*}{ Site IV } & Measured & 3.4 & 26.1 & 436 & 51.0 & 26.9 & 65.5 & 61.2 \\
\hline & Modeled & 3.1 & 42.7 & 494 & 57.0 & 28.2 & 76.9 & 48.1 \\
\hline & R-correlation & & 0.52 & 0.39 & 0.39 & & & 0.27 \\
\hline & F-value & & 22.5 & 10.6 & 10.8 & & & 4.7 \\
\hline & $P(F)$ & & $1.3 \times 10^{-5}$ & 0.0018 & 0.0017 & & & 0.034 \\
\hline \multirow[t]{5}{*}{ Site V } & Measured & 2.6 & 20.0 & 412 & 49.1 & 24.0 & 43.8 & 44.4 \\
\hline & Modeled & 2.1 & 18.6 & 405 & 40.8 & 19.8 & 36.1 & 26.7 \\
\hline & R-correlation & 0.30 & 0.64 & 0.75 & 0.79 & 0.48 & & 0.54 \\
\hline & F-value & 5.9 & 43.2 & 79.4 & 103 & 18.4 & & 24.8 \\
\hline & $P(F)$ & 0.018 & $1.3 \times 10^{-8}$ & $1.2 \times 10^{-12}$ & $1.0 \times 10^{-14}$ & $6.6 \times 10^{-5}$ & & $5.5 \times 10^{-6}$ \\
\hline
\end{tabular}

variables are not correlated) are shown in Table 4 . If $F$ is smaller than 4.0 or if $P(F)$ is larger than 0.1 , the correlation is considered insignificant. Only the pairs that satisfy both $F>4.0$ and $P<0.1$ are shown in the table.

Due to the very close $V_{\mathrm{d}}$ values from the model estimations and the measurements, as discussed in Sect. 3.2, the modeled and the measured annual average dry deposition fluxes were also very close in value, e.g. within $20 \%$ for most of the cases for all of the metal species except $\mathrm{Pb}$. The model estimated that the $\mathrm{Pb}$ fluxes were around $30 \%$ lower than the measured fluxes.

Nearly $70 \%$ of all of the cases showed significant correlations between the modeled and the measured fluxes as shown in Table 4. This is surprising considering that there was little correlation between the modeled and measured $V_{\mathrm{d}}$ values, as discussed in Sect. 3.2. One reason for the significant correlation between the modeled and the measured fluxes could be because they both depended on the measured concentrations. For example, Fe and $\mathrm{Zn}$ were two species whose measured fluxes correlated well with their measured concentrations, as discussed in Sect. 2.4. These two species were also found to have good correlations between their modeled and measured fluxes (Table 4). Another example is Mn, which had much better correlation between its measured fluxes and concentrations at Sites II to V than at Site I (Fig. 3); in comparison, correlations between its modeled and measured fluxes at Sites II to $\mathrm{V}$ were also significant, but no correlations were found at Site I. Table 4 also shows that the worst performances were for $\mathrm{Cu}$ and $\mathrm{As}$, which are consistent with the low correlations between their measured fluxes and their measured concentrations (Fig. S3). It can be seen that the cases with (slightly) better correlations between their measured fluxes and concentrations do not always have better correlations between their modeled and their measured fluxes, and vice versa (compare the values for As at Site I with its values at Sites II and III). This might have been caused by the uncertainties in the modeled $V_{\mathrm{d}} \mathrm{s}$ (and thus the fluxes).

\section{Conclusions and discussions}

The measurements of the daily air concentrations and the dry deposition fluxes of seven metal species conducted at five sites in central Taiwan during a one year period and the dry deposition velocities generated from these measurements were summarized in this study. Annual average 


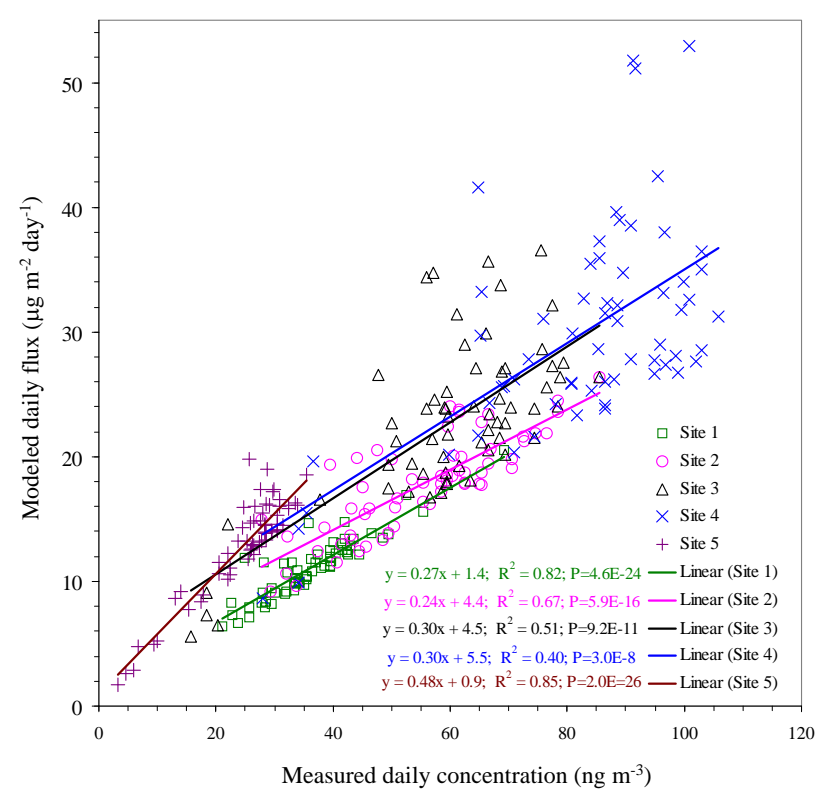

Fig. 5. Correlations between the modeled daily fluxes $\left(\mu \mathrm{g} \mathrm{m}^{-2} \mathrm{day}^{-1}\right)$ and the measured daily concentrations $\left(\mathrm{ng} \mathrm{m}^{-3}\right)$ for $\mathrm{Mn}$ at the five sites.

concentrations were found to be the lowest in the summer for all of the seven species and at all of the locations; however, the seasonal variations were generally small, e.g. mostly within a few ten percent. The highest concentrations appeared during different seasons for different species, but were generally consistent from site to site due to the fact that the five sites are all within a small region several hundred square kilometres in size. Annual average dry deposition fluxes were on the order of 3,20,400,50, 25, 50, and $50 \mu \mathrm{g} \mathrm{m}^{-2} \mathrm{day}^{-1}$ for $\mathrm{As}, \mathrm{Mn}, \mathrm{Fe}, \mathrm{Zn}, \mathrm{Cr}, \mathrm{Cu}$, and $\mathrm{Pb}$, respectively. The seasonal variations in the deposition fluxes were mostly determined by the air concentrations and, to a lesser extent, by the deposition velocities. Geographical variations in the deposition fluxes were smaller than the geographical variations in the air concentrations since the wetland site that had the lowest air concentrations also happened to have the largest deposition velocities. The moderate-to-good correlations between the measured fluxes and air concentrations for several of the species provided some confidence in the measurement of the fluxes using surrogate surfaces; however, large uncertainties for several of the species at several of the sites might exist, as can be seen by the lack of a correlation between the measured fluxes and concentrations.

Annual dry deposition velocities for the seven metal species ranged from 0.18 to $2.22 \mathrm{~cm} \mathrm{~s}^{-1}$. These measured deposition velocities can be mainly reproduced using a sizesegregated particle dry preposition model with assumed particle size distributions. However, the modeled and the measured daily deposition velocities had weak correlations, despite their good agreement in annual average values. Sensi- tivity tests suggest that, for the several metal species considered in the present study, mass fraction of particles larger than $10 \mu \mathrm{m}$ played a dominant role in the total deposition fluxes due to the much higher (e.g. by a factor of 20) deposition velocities of these large particles compared to those of fine $\left(\mathrm{PM}_{2.5}\right)$ and coarse $\left(\mathrm{PM}_{2.5-10}\right)$ particles. If no detailed size distribution is available, to accurately estimate the dry deposition fluxes of trace metals using an inferential method, knowledge of the mass faction of $\mathrm{PM}_{2.5}, \mathrm{PM}_{2.5-10}$, and particles larger than $10 \mu \mathrm{m}$ is required.

In most air-quality and climate studies, both particle number and mass concentrations need to be considered. Thus, size-resolved particle dry deposition models are needed. However, in other environmental assessments, the input of dry deposition to various ecosystems is the only concern. In this case, a simple empirical model estimating dry deposition from monitored air concentrations is preferred. Several earlier studies generated simple regression formulas, for certain metal species, based on the limited measurement data (such as the data presented in this study). Due to the many factors affecting the dry deposition process, empirical models based on the limited data are likely not "universally" applicable.

The best approach for the development of such empirical models would be to use a size-resolved model (or an ensemble of size-resolved models) to conduct a large set of sensitivity tests in order to identify the key parameters that need to be included in the empirical models. Key parameters likely include surface roughness length, leaf area index, friction velocity, surface-layer stability (Monin-Obukou length), etc. An additional land-use dependent empirical constant is also likely needed since the particle collection efficiencies for the various landscapes are different. Typical land types should include "broadleaf trees", "needleleaf trees", "agricultural/grass lands", bare soil, water, and urban land. Residential areas (e.g. suburban) can be weighted from a combination of urban land, trees and grasslands. Field flux data collected at various locations can then be used to validate the empirical models developed from the simplification of existing more sophisticated models.

It is also recommended that the empirical models should not be "particle-species"-dependant (in order to avoid developing too many models); instead, they should be for certain particle size ranges, for example $\mathrm{PM}_{2.5}, \mathrm{PM}_{2.5-10}$, and $\mathrm{PM}_{10+}$. Very small particles (e.g. 0.001 to $1.0 \mu \mathrm{m}$ ), despite having large deposition velocities and high number concentrations, generally have low mass concentrations and thus are not important to the total dry deposition budget. If empirical models are developed for the three modes $\left(\mathrm{PM}_{2.5}, \mathrm{PM}_{2.5-10}\right.$, and $\mathrm{PM}_{10+}$ ), as long as the mass fractions in these size ranges are known or can be reasonably assumed (such as using the information reviewed in Sect. 3.1 of this study), dry deposition of any particle species can be simply estimated. 
Supplementary material related to this article is available online at: http://www.atmos-chem-phys.net/12/ 3405/2012/acp-12-3405-2012-supplement.pdf.

Acknowledgements. We greatly appreciate the National Science Council of the R.O.C. (Taiwan) for the financial support under the project No. NSC 99-2221-E-241-006-MY3.

Edited by: J. G. Murphy

\section{References}

Allen, A. G., Nemitz, E., Shia, J. P., Harrison, R. M., and Greenwood, J. C.: Size distributions of trace metals in atmospheric aerosols in the United Kingdom, Atmos. Environ., 35, 45814591, 2001.

Al-Momani, I. F., Momani, K. A., Jaradat, Q. M., Massadeh, A. M., Yousef, Y. A., and Alomary, A. A.: Atmospheric deposition of major and trace elements in Amman, Jordan, Environ. Monit. Assess., 136, 209-218, 2008.

Akhlaghi, Y. and Kompany-Zareh, M.: Comparing radial basis function and feed-forward neural networks assisted by linear discriminant or principal component analysis for simultaneous spectrophotometric quantification of mercury and copper, Anal. Chim. Ac., 537, 331-338, 2005.

Brüggemann, E., Gerwig, H., Gnauk, Th., Müller, K., and Herrmann, H.: Influence of seasons, air mass origin and day of the week on size-segregated chemical composition of aerosol particles at a kerbside, Atmos. Environ., 43, 2456-2463, 2009.

Chao, C. Y. and Wong, K. K.: Residential indoor $\mathrm{PM}_{10}$ and $\mathrm{PM}_{10}$ in Hong Kong and the elemental composition, Atmos. Environ., 36, 265-277, 2002.

Cho, S.-H., Richmond-Bryant, J., Thornburg, J., Portzer, J., Vanderpool, R., Cavender, K., and Rice, J: A literature review of concentrations and size distributions of ambient airborne $\mathrm{Pb}$ containing particulate matter, Atmos. Environ., 45, 5005-5015, 2011.

de P. Pereira, P. A., Lopes, W. A., Carvalho, L. S., da Rocha, G. O., de Carvalho Bahia, N., Loyola, J., Quiterio, S. L., Escaleira, V., Arbilla, G., and de Andrade, J. B.: Atmospheric concentrations and dry deposition fluxes of particulate trace metals in Salvador, Bahia, Brazil, Atmos. Environ., 41, 7837-7850, 2007.

Fang, G. C., Wu, Y. S., Huang, S. H., and Rau, J. Y.: Dry deposition (downward, upward) concentration study of particulates and heavy metals during daytime, nighttime period at the traffic sampling site of Sha-Lu, Taiwan, Chemosphere, 56, 509-518, 2004.

Fang, G. C., Wu, Y. S., Chang, S. Y., Lin, J. B., and Lin, J. G.: Overall dry deposition velocities of trace elements measured at harbor and traffic site in central Taiwan, Chemosphere, 67, 966974, 2007a.

Fang, G. C., Wu, Y. S., Lee, W. J., Chou, T. Y., and Lin, I. C.: Ambient air particulates, metallic elements, dry deposition and concentrations at Taichung Airport, Taiwan, Atmos. Res., 84, 280289, 2007b.

Flechard, C. R., Nemitz, E., Smith, R. I., Fowler, D., Vermeulen, A. T., Bleeker, A., Erisman, J. W., Simpson, D., Zhang, L., Tang, Y. S., and Sutton, M. A.: Dry deposition of reactive nitrogen to European ecosystems: a comparison of inferential models across the NitroEurope network, Atmos. Chem. Phys., 11, 2703-2728, doi:10.5194/acp-11-2703-2011, 2011.

Funasaka, K., Sakai, M., Shinya, M., Miyazaki, T., Kamiura, T., Kaneco, S., Ohta, K., and Fujita, T.: Size distribution and characteristics of atmospheric inorganic particles by regional comparative study in Urban Osaka, Japan, Atmos. Environ., 37, 45974605, 2003.

Holsen, T. M. and Noll, K. E.: Dry deposition of atmospheric particles: application of current models to ambient data, Environ. Sci. Technol., 26, 1802-1814, 1992.

Kasahara, M., Park, J. H., and Yamamoto, K.: Characterization of atmospheric aerosols separated by particle size and water solubility using PIXE analysis, Nuclear Instruments and Methods in Physics Research, Section B: Beam Interactions with Materials and Atoms, 109-110, 471-475, 1996.

Karanasiou, A. A., Sitaras, I. E., Siskos, P. A., and Eleftheriadis, K.: Size distribution and sources of trace metals and n-alkanes in the Athens urban aerosol during summer, Atmos. Environ., 41, 2368-2381, 2007.

Kim, K. H., Mishra, V. K., Kang, C. H., Choi, K. C., Kim, Y. J., and Kim, D. S.: The ionic compositions of fine and coarse particle fractions in the two urban areas of Korea, J. Environ. Manag., 78, 170-182, 2006.

Koçak, M., Kubilay, N., Herut, B., and Nimmo, M.: Dry atmospheric fluxes of trace metals ( $\mathrm{Al}, \mathrm{Fe}, \mathrm{Mn}, \mathrm{Pb}, \mathrm{Cd}, \mathrm{Zn}, \mathrm{Cu}$ ) over the Levantine Basin: A refined assessment, Atmos. Environ., 39, 7330-7341, 2005.

Loska, K. and Wiechuła, D.: Application of principal component analysis for the estimation of source of heavy metal contamination in surface sediments from the Rybnik Reservoir, Chemosphere, 51, 723-733, 2003.

Lu, R., Turco, R. P., Stolzenbach, K., Friedlander, S. K., Xiong, C., Schiff, K., Tiefenthaler, L., and Wang, G.: Dry deposition of airborne trace metals on the Los Angeles Basin and adjacent coastal waters, J. Geophys. Res., 108, 4074, doi:1029/2001JD001446, 2003.

Makkonen, U., Hellén, H., Anttila, P., and Ferm, M.: Size distribution and chemical composition of airborne particles in southeastern Finland during different seasons and wildfire episodes in 2006, Sci. Total Environ., 408, 644-651, 2010.

Migon, C., Journel, B., and Nicolas E.: Measurement of trace metal wet, dry and total atmospheric fluxes over the Ligurian Sea, Atmos. Environ., 31, 889-896, 1997.

Monarca, S., Crebelli, R., Feretti, D., Zanardini, A., Fuselli, S., Filini, L., Resola, S., Bonardelli, P. G., and Nardi, G.: Mutagens and carcinogens in size-classified air particulates of a Northern Italian town, Sci. Total Environ., 205, 137-144, 1997.

Napier, F., D'Arcy, B., and Jefferies, C.: A review of vehicle related metals and polycyclic aromatic hydrocarbons in the UK environment, Desalination, 226, 143-150, 2008.

Odabasi, M., Muezzinoglu, A., and Bozlaker, A.: Ambient concentrations and dry deposition fluxes of trace elements in Izmir, Turkey, Atmos. Environ., 36, 5841-5851, 2002.

Paode, R. D., Sofuoglu, S. C., Sivadechathep, J., Noll, K. E., Holsen, T. M., and Keeler, G. J.: Deposition fluxes and mass size distributions of $\mathrm{Pb}, \mathrm{Cu}$, and $\mathrm{Zn}$ measured in southern Lake Michigan during AEOLOS, Environ. Sci. Technol., 32, 1629 $1635,1998$. 
Petroff, A. and Zhang, L.: Development and validation of a size-resolved particle dry deposition scheme for application in aerosol transport models, Geosci. Model Dev., 3, 753-769, doi:10.5194/gmd-3-753-2010, 2010.

Pirrone, N., Keeler, G. J., and Warner, P. O.: Trends of ambient concentrations and deposition fluxes of particulate trace metals in Detroit from 1982 to 1992, Sci. Total Environ., 162, 43-61, 1995.

Rojas, C. M., Injuk, J., and van Grieken, R. E.: Dry and wet deposiiton fluxes of $\mathrm{Cd}, \mathrm{Cu}, \mathrm{Pb}$ and $\mathrm{Zn}$ into the SouthernBright of the North Sea, Atmos. Environ., 27, 251-259, 1993.

Sabin, L. D., Lim, J. H., Stolzenbach, K. D., and Schiff, K. C.: Atmospheric dry deposition of trace metals in the coastal region of Los Angeles, California, USA, Environmental Toxicology and Chemistry, 25, 2334-2341, 2006.

Sakata, M. and Marumoto, K.: Dry Deposition Fluxes and Deposition Velocities of Trace Metals in the Tokyo Metropolitan Area Measured with a Water Surface Sampler, Environ. Sci. Technol., 38, 2190-2197, 2004.

Sakata, M., Marumoto, K., Narukawa, M., and Asakura, K.: Regional variations in wet and dry deposition fluxes of trace elements in Japan, Atmos. Environ., 40, 521-531, 2006.

Sakate, M., Tani, Y., and Takagi, T.: Wet and dry deposition fluxes of trace elements in Tokyo Bay, Atmos. Environ., 42, 59135922, 2008.

Samara, C. and Voutsa, D.: Size distribution of airborne particulate matter and associated heavy metals in the roadside environment, Chemosphere, 59, 1197-1206, 2005.

Schwede, D. B., Zhang, L., Vet, R., and Lear G.: An intercomparison of the deposition models used in the CASTNET and CAPMoN networks, Atmos. Environ., 45, 1337-1346, 2011.

Singh, M., Jaquesb, P. A., and Sioutas, C.: Size distribution and diurnal characteristics of particle-bound metals in source and receptor sites of the Los Angeles Basin, Atmos. Environ., 36, 1675-1689, 2002.

Singh, K. P., Malik, A., and Sinha, S.: Water quality assessment and apportionment of pollution sources of Gomti river (India) using multivariate statistical techniques-a case study, Anal. Chim. Ac., 538, 355-374, 2005.

Sofuoglu, S. C., Paode, R. D., Sivadechathep, J., Noll, K. E., Holsen, T. M., and Keeler, G. J.: Dry deposition fluxes and atmospheric size distributions of mass, $\mathrm{Al}$, and $\mathrm{Mg}$ measured in southern Lake Michigan during AEOLOS, Aerosol Sci. Technol., 29, 281-293, 1998.

Tasdemir, Y. and Kural, C.: Atmospheric dry deposition fluxes of trace elements measured in Bursa, Turkey, Environ. Pollut., 138, 462-472, 2005.
Tasdemir, Y., Kural, C., Cindoruk, S. S., and Vardar, N.: Assessment of trace element concentrations and their estimated dry deposition fluxes in an urban atmosphere, Atmos. Res., 81, 17-35, 2006.

Turšič, J., Podkrajsek, B., Grgic, I., Ctyroky, P., Berner, A., Dusek, U., and Hitzenberger, R.: Chemical composition and hygroscopic properties of size-segregated aerosol particles collected at the Adriatic coast of Slovenia, Chemosphere, 63, 1193-1202, 2006.

Wang, X., Sato, T., and Xing, B.: Size distribution and anthropogenic sources apportionment of airborne trace metals in Kanazawa, Japan, Chemosphere, 65, 2440-2448, 2006.

Wu, Y. S., Fang, G. C., Chen, J. C., Lin, C. P., Huang, S. H., Rau, J. Y., and Lin, J. G.: Ambient air particulate dry deposition, concentrations and metallic elements at Taichung Harbor near Taiwan Strait, Atmos. Res., 79, 52-66, 2006.

Wu, Y. S., Fang, G. C., and Lin, S. H.: Season variations for metallic elements compositions study in plant Bidenens pilosa L. var. radiate Sch. in central Taiwan, Environ. Monit. Assess., 168, 255267, 2010.

Yi, S. M., Shahin, U., Sivadechathep, J., Sofuoglu, S. C., and Holsen, T. M.: Overall elemental dry deposition velocities measured around Lake Michigan, Atmos. Environ., 35, 1133-1140, 2001.

Yi, S. M., Totten, L. A., Thota, S., Yan, S., Offenberg, J. H., Eisenreich, S. J., Garney, J., and Holsen, T. M.: Atmospheric dry deposition of trace elements measured around the urban and industrially impacted NY-NJ harbor, Atmos. Environ., 40, 6626-6637, 2006.

Zhang, L., Gong, S., Padro, J., and Barrie, L. A.: A size-segregated particle dry deposition scheme for an atmospheric aerosol module, Atmos. Environ., 35, 549-560, 2001.

Zhang, L., Brook, J. R., and Vet, R.: A revised parameterization for gaseous dry deposition in air-quality models, Atmos. Chem. Phys., 3, 2067-2082, doi:10.5194/acp-3-2067-2003, 2003.

Zota, A. R., Willis, R., Jim, R., Norris, G. A., Shine, J. P., Duvall, R. M., Schaider, L. A., and Spengler, J. D.: Impact of mine waste on airborne respirable particulates in Northeastern Oklahoma, United States, J. Air Waste Manage. Assoc., 59, 13471357, 2009.

Zufall, M. J., Davidson, C. I., Caffrey, P. F., and Ondov, J. M.: Airborne concentrations and dry deposition fluxes of particulate species to surrogate surfaces deployed in Southern Lake Michigan, Environ. Sci. Technol., 32, 1623-1628, 1998. 